\title{
RANCANG BANGUN ALAT PRODUKSI "BANDREK" UNTUK MENGOPTIMALKAN PROSES KRISTALISASI DAN MEMINIMALKAN RESIDU PRODUK
}

\author{
Ratih Setyaningrum \\ Fakultas Teknik, Program Studi Teknik Industri \\ Universitas Dian Nuswantoro \\ Email: ratihha@gmail.com \\ Jazuli \\ Fakultas Teknik, Program Studi Teknik Industri \\ Universitas Dian Nuswantoro \\ Email: jazuli.st.meng@gmail.com \\ Kurniawati Puji Lestari \\ Fakultas Teknik, Program Studi Teknik Industri \\ Universitas Dian Nuswantoro \\ Email:kplestari@gmail.com
}

\begin{abstract}
ABSTRAK
Proses pengkristalan serbuk bandrek manual pada UKM Ayuk dusun Mangun, Limbangan, mengakibatkan kelelahan pekerja dan menghasilkan residu sebanyak 40\% berupa gumpalan kristal besar menyerupai permen. Residu dihasilkan pada kondisi suhu pemasakan $85-90^{\circ} \mathrm{C}$ dan kecepatan aduk $40 \mathrm{Rpm}$ dengan tenaga manusia. Berdasarkan permasalahan tersebut peneliti merancang alat pengkristal bandrek menggunakan Desain Eksperimen Taguchi untuk mencapai kondisi ideal guna meminimalkan residu dan mengurangi kerugian secara kuantitatif. Kondisi ideal diperoleh melalui beberapa eksperimen menggunakan desain eksperimen menggunakan alat produksi bandrek. Alat yang dirancang digunakan dalam percobaan sebanyak 16 kali sehingga menghasilkan kondisi ideal atau kondisi optimum pada setting suhu $95^{\circ}-100^{\circ} \mathrm{C}$ dan kecepatan aduk dengan $80 \mathrm{Rpm}$. Terlihat adanya penurunan jumlah residu yang sebelumnya $40 \%$ menjadi $19 \%$ pada hasil implementasi.
\end{abstract}

Kata kunci: perancangan; bandrek; kristalisasi; residu produk.

\section{ABSTRACT}

The crystallization process of "Bandrek" powder at the Ayuk UKM in Mangun, Limbangan is a trigger of worker fatigue. There are produced a residue of $40 \%$ in the form of large crystal clumps resembling candy. The residue is produced under conditions of cooking temperatures of $85-90^{\circ} \mathrm{C}$ and stirring speeds of 40 Rpm with human power. Based on these problems the researchers designed a bandrek crystallizer using the Taguchi experiment design to achieve ideal conditions to minimize residuals and reduce losses quantitatively. Ideal conditions get from several experiment using design of experiment with "bandrek" production tool. The tool designed is used in experiments 16 times so as to produce ideal conditions or optimum conditions at a temperature setting of $95^{\circ}-100^{\circ} \mathrm{C}$ and stirring speed with $80 \mathrm{Rpm}$. There was a decrease in the amount of residue that was previously $40 \%$ to $19 \%$ in the results of the implementation.

Keywords: design; bandrek; crystallization; residue product.

\section{PENDAHULUAN}

Proses kristalisasi serbuk bandrek dilakukan dengan proses pemanasan pada suhu tertentu. Proses tersebut dikerjakan dalam waktu 90 menit dengan cara mengaduk adonan secara terus menerus hingga kadar air berkurang. Proses pengkristalan serbuk secara manual mengakibatkan kelelahan pekerja, karena harus terus mengaduk agar bandrek tidak gosong di sekitar wajan. Selain itu karena suhu yang tidak dikendalikan dengan konstan dan kecepatan aduk yang tidak sesuai menghasilkan residu sebanyak $40 \%$ berupa gumpalan kristal besar menyerupai permen. Residu tersebut dihasilkan karena suhu pemasakan $85-90^{\circ} \mathrm{C}$ dan kecepatan aduk 40 rpm dengan tenaga manusia. Hasil kristalisasi bandrek disajikan pada Gambar 1. 

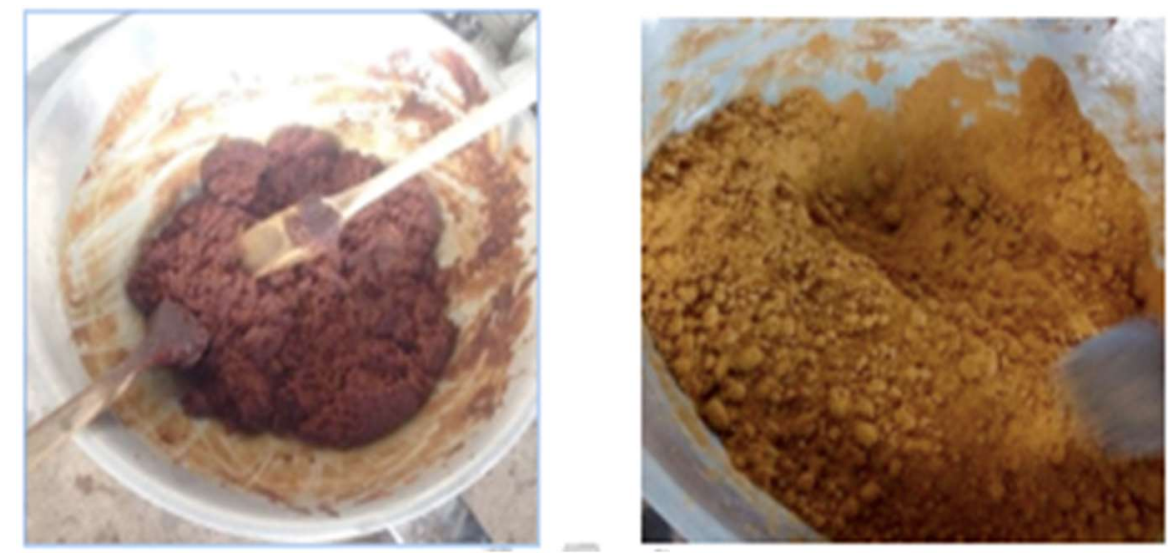

Gambar 1. Kristalisasi Bandrek Menjadi Serbuk

Disamping itu, target produksi yang dihasilkan belum tercapai karena serbuk bandrek masih menggumpal karena proses kristalisasi yang belum optimal. Target yang tidak tercapai sekitar $40 \%$. Oleh sebab itu perlu dilakukan optimalisasi proses kristalisasi bandrek agar residu produk berkurang dan target produksi terpenuhi. Berdasarkan permasalahan tersebut, tujuan penelitian ini adalah merancang bangun alat produksi "Bandrek" untuk mengoptimalkan proses kristalisasi dan mengurangi residu produk.

Luaran penelitian ini diharapkan akan mampu meminimalkan residu yang dihasilkan dari proses produksi bandrek dan UKM Ayuk akan mampu memenuhi target produksinya.

Beberapa penelitian tentang optimalisasi proses kristalisasi dilakukan menggunakan beberapa metode fisika (1). Metode desain eksperimen yang diterapkan pada eksperimen kekuatan tarik, proses bubut (2), optimalisasi mesin CNC (2) dan proses pengecoran (3) . Metode Taguchi digunakan pada produk tutup botol (4). Berdasarkan penelitian sebelumnya (5)(1), penelitian ini akan menggunakan metode desain eksperimen untuk mendukung proses rancang bangun alat produksi bandrek sehingga bisa mengoptimalkan kristalisasi serbuk bandrek.

\section{METODOLOGI PENELITIAN}

Penelitian ini menggunakan metode desain eksperimen (6). Tahapan perancangan alat dengan metode desain eksperimen Taguchi (7) dan meliputi tahap persiapan eksperimen, identifikasi karakteristik kualitas, pengukuran kondisi aktual. Tahap perencanaan eksperimen Taguchi: mengidentifikasi variabel respon, menentukan setting level setiap faktor dan memilih Orthogonal Array dan jumlah variasi percobaan. Tahap pelaksanaan eksperimen Taguchi: perancangan alat, melakukan eksperimen dan pengolahan data dan menganalisa hasil data.

\subsection{Factors dan Levels dari Eksperimen untuk Model yang di Bangun}

Desain eksperimen dengan 2 faktor dan 4 level yang dikendalilan pada proses pengkristalan serbuk bandrek. Percobaan dengan beberapa faktor dilakukan seperti yang disajikan pada Tabel 1. Percobaan pada level 1 dengan suhu 80-90 derajat celsicus dan kecepatan aduk 40 rpm. Percobaan level 2 dengan suhu 90-95 derajat celcius dan kecepatan aduk $60 \mathrm{rpm}$. Percobaan level 2 dengan suhu 95-100 derajat celcius dan kecepatan aduk $80 \mathrm{rpm}$. Percobaan level 2 dengan suhu 100-105 derajat celcius dan kecepatan aduk $60 \mathrm{rpm}$. Setiap percobaan pada setiap levelnya dilakukan beberapa kali.

Tabel 1. Faktor dan level desain eksperimen

\begin{tabular}{ccc}
\hline \multirow{2}{*}{ Level } & \multicolumn{2}{c}{ Factors } \\
\cline { 2 - 3 } & $\mathbf{A}$ & B \\
\cline { 2 - 3 } & Suhu $\left({ }^{\circ} \mathbf{C}\right)$ & Kecepatan Aduk (Rpm) \\
\cline { 2 - 3 } 1 & $85-90$ & 40 \\
2 & $90-95$ & 60 \\
3 & $95-100$ & 80 \\
4 & $100-105$ & 100 \\
\hline
\end{tabular}


Hasil desain eksperimen menunjukkan 16 kali percobaan dan persentase residu yang dihasilkan dari setiap percobaan ditunjukkan pada Tabel 4. Kondisi ideal percobaan dipilih berdasarkan jumlah residu terkecil yang dihasilkan dari setiap percobaan.

\subsection{Pemilihan Orthogonal Array}

Orthogonal Array yang digunakan menandakan bahwa untuk jumlah residu dilakukan percobaan sebanyak 16 kali dengan 15 faktor kontrol seperti yang disajikan pada Tabel 2.

Tabel 2. Pemilihan orthogonal array dan jumlah DoF yang sesuai

\begin{tabular}{cc}
\hline Jumlah DoF & Orthogonal Array \\
\hline $2-3$ & L4 \\
$4-7$ & L8 \\
$8-11$ & L12 \\
$12-15$ & L16 \\
\hline
\end{tabular}

\section{HASIL DAN PEMBAHASAN}

Hasil desain eksperimen dengan perlakuan suhu dan kecepatan aduk menghasilkan residu seperti yang disajikan pada Tabel 4. Pemilihan pengaturan level dari faktor yang paling optimum dengan memilih $\mathrm{S} / \mathrm{N}$ ratio yang paling maksimal yaitu pada level $3\left(95^{\circ}-100^{\circ} \mathrm{C}\right)$ dan kecepatan aduk dengan Level $3(80 \mathrm{Rpm})$ seperti yang disajikan pada Gambar 2.

Tabel 4. Hasil percobaan pengkristalan bandrek

\begin{tabular}{cccc}
\hline No. & Suhu & Kecepatan Aduk & Residu \\
\hline 1 & $85-90$ & 40 & $35 \%$ \\
2 & $85-90$ & 60 & $30 \%$ \\
3 & $85-90$ & 80 & $33 \%$ \\
4 & $85-90$ & 100 & $30 \%$ \\
5 & $90-95$ & 40 & $25 \%$ \\
6 & $90-95$ & 60 & $25 \%$ \\
7 & $90-95$ & 80 & $23 \%$ \\
8 & $90-95$ & 100 & $24 \%$ \\
9 & $95-100$ & 40 & $24 \%$ \\
10 & $95-100$ & 60 & $20 \%$ \\
11 & $95-100$ & 80 & $21 \%$ \\
12 & $95-100$ & 100 & $23 \%$ \\
13 & $100-105$ & 40 & $29 \%$ \\
14 & $100-105$ & 60 & $34 \%$ \\
15 & $100-105$ & 80 & $30 \%$ \\
16 & $100-105$ & 100 & $36 \%$ \\
\hline & & &
\end{tabular}

Hasil eksperimen yang disajikan pada Tabel 2 menunjukkan bahwa level 3 pada pada suhu 95-100 derajat celcius dengan kecepatan aduk bervariasi dari $40 \mathrm{rpm}, 60 \mathrm{rpm}, 80 \mathrm{rpm}$ dan $100 \mathrm{rpm}$. Residu rendah ada pada kondisi suhu 95-100 derajat celcius dengan kecepatan aduk $60 \mathrm{rpm}$ menghasilkan residu 20\% dan kecepatan aduk $80 \mathrm{rpm}$ menghasilkan residu $21 \%$.

Hasil rancang bangun alat produksi bandrek seperti disajikan pada Gambar 3. Dengan alat tersebut diperoleh perbaikan proses kristalisasi sehingga mampu meminimalkan residu bandrek seperti disajikan pada Tabel 5. 


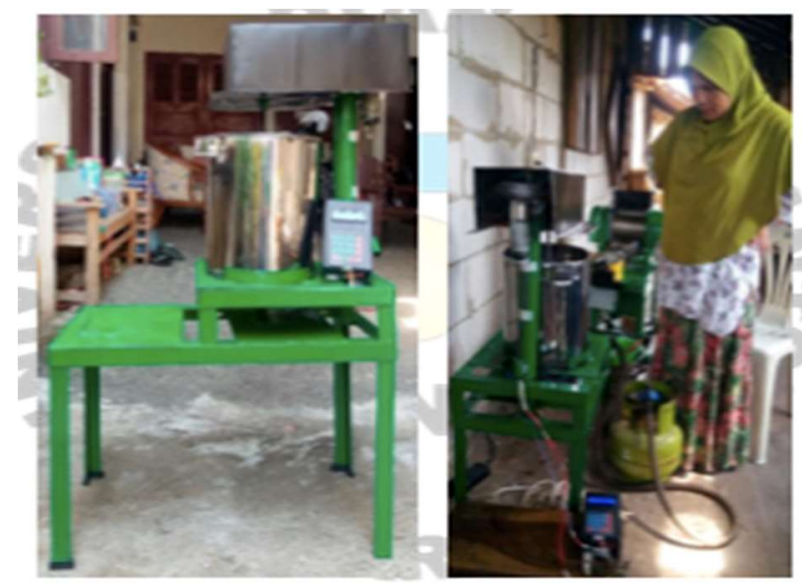

Gambar 3. Desain Alat Produksi Bandrek

Desain alat produksi bandrek yang disajikan pada Gambar 3 menunjukkan dimensi alat saat akan digunakan oleh pekerja dengan posisi berdiri. Pekerja menggunakan alat produksi bandrek yang kemudian akan dievaluasi residu yang dihasilkan pada alat tersebut. Hasil residu pada proses produksi dengan menggunakan alat baru akan dibandingkan dengan proses produksi sebelum menggunakan alat ini. Hasil perbandingan jumlah residu proses sebelum dan setelah menggunakan alat disajikan pada Tabel 5.

Tabel 5. Perbandingan jumlah residu yang dihasilkan

\begin{tabular}{ccccc}
\hline No. & Proses & Suhu $\left({ }^{\circ} \mathbf{C}\right)$ & Kecepatan Aduk (Rpm) & Residu \\
\hline 1 & Sebelum menggunakan alat & $85-90$ & 40 & $40 \%$ \\
2 & Sesudah menggunakan alat & $95-100$ & 80 & $20 \%$ \\
\hline
\end{tabular}

Hasil perbandingan dari kondisi sebelum dan sesudah menggunakan alat memiliki perbedaan yang cukup signifikan. Alat pengkristal bandrek yang digunakan menunjukan kinerja yang efektif, artinya sudah sesuai dengan yang diharapkan. Pada Tabel 5 menunjukan adanya penurunan jumlah residu yang sebelumnya $40 \%$ menjadi $19 \%$.

Selain itu alat pengkristal bandrek juga memiliki kemampuan sesuai fungsinya dengan baik, artinya lebih menghemat tenaga pekerja. Desain alat juga sudah sesuai dengan dimensi tubuh orang Indonesia, sehingga pekerja akan lebih aman dan nyaman ketika mengoperasikan.

\section{KESIMPULAN}

Rancang bangun alat produksi "Bandrek" mampu mengoptimalkan proses kristalisasi serbuk bandrek. Residu yang dihasilkan pada proses kristalisasi mampu turun sebesar $50 \%$. Kondisi ideal proses produksi bandrek pada suhu 95-100 ${ }^{\circ} \mathrm{C}$ dengan kecepatan aduk $80 \mathrm{rpm}$.

Proses produksi menjadi relatif cepat sehingga diharapkan mampu memenuhi target produksi UKM. Pada penelitian selanjutnya bisa dikaji postur kerja proses produksinya sehingga kinerja pegawai dapat dievaluasi.

\section{DAFTAR PUSTAKA}

[1] Fatchurrochman M, Romyta F. 83 Mesin Kristalisasi Serbuk Untuk Ukm Jamu Varagus Di Kecamatan Pegandon Kendal M. Fatchurrochman Dan Faizal Romyta Sydore. :3-6.

[2] Sidi P, Wahyudi MT, Teknik J, Kapal P, Perkapalan P, Surabaya N. Aplikasi Metoda Taguchi Untuk Mengetahui Optimasi Kebulatan Pada Proses Bubut Cnc. 2013;4(2):101-8.

[3] San GS, Mesin JT, Industri FT, Petra UK. Desain Eksperimen Untuk Mengoptimalkan Proses Pengecoran Saluran Keluar Teko. :5-10.

[4] Prasanko AW, Djumhariyanto D, Triono A. Analisis Parameter Injection Molding Terhadap Waktu Siklus Dan Cacat Flash Produk Tutup Botol 180 Ml Menggunakan Metode Taguchi,. 2017;10(April):45-50.

[5] Ilmiah P, Nindhira AL, Studi P, Industri T, Teknik F, Surakarta UM. Desain Eksperimen Untuk Pengendalian Kadar Air Jamu Simplisia. 2016;

[6] Edition S. M Ultivariate Overview Of Multivariate Methods.

[7] Amelia V. Kehalusan Gula Menggunakan Metode Taguchi. 